On admission the patient was in fairly poor general health, and the knee was swollen, warm, and tender. Erythrocyte sedimentation rate was $122 \mathrm{~mm}$ in first hour, haemoglobin concentration was $10.8 \mathrm{~g} / \mathrm{dl}$, IgG $19 \mathrm{~g} / \mathrm{l}$; tests for rheumatoid factor and antinuclear antibody gave negative results. Treatment with prednisolone and hydroxychloroquine was started, and his knee was repeatedly injected with topical steroids. His condition improved generally on this regimen, ESR fell to $9 \mathrm{~mm}$ in first hour and haemoglobin concentration rose to $13.9 \mathrm{~g} / \mathrm{dl}$, but the knee remained swollen.

At arthroscopy, abundant yellowish-white material was seen in a hyperaemic joint cavity. Synovial fluid injected into blood-culture bottles showed fungal growth after four days: the fungus was identified as $P$ boydii. At microscopy of synovial fluid unusual large foamy cells were prominent but no fungal elements were found, even on review of cytocentrifugal preparations and sections from the biopsy specimen. Fluid drawn one week later gave the same results on culture and microscopy.

Tests for humoral and cellular immunity gave normal results. The patient was treated with systemic and local amphotericin B (tota 441000 IU (441 mg)) with apparent success but six months later the knee became swollen again, and $P$ boydii was isolated again. The fungus was sensitive to miconazole: treatment with this drug was started and a synovectomy performed. The drug had to be discontinued after 22 infusions because of haematuria. Amphotericin was reintroduced but stopped as transaminase values rose and fever spikes appeared. The patient was subfebrile, erythrocyte sedimentation rate was high, and the knee remained swollen and tender. Fortunately, the ketoconazole sensitivity assay performed at this point gave a minimal inhibitory concentration of $0.4-0.8 \mathrm{mg} / \mathrm{l}$. He was given 100 mg oral ketoconazole thrice daily, which produced a maximal serum concentration of $2.5 \mathrm{mg} / \mathrm{l}$ : treatment was continued for a year. The boy has been without drug treatment for 16 months with no sign of infection. His knee is painless but totally stiff.

\section{Discussion}

Fungal arthritis often develops after accidents outdoors. ${ }^{4}$ Our case shows that the disease is not encountered exclusively in warmer countries. Undoubtedly fungal arthritis is rare elsewhere, but it could appear to be even rarer, as the diagnosis may be missed by routine procedures. With the introduction of a new treatment of choice for most fungal infections ${ }^{5}$ it is of practical importance to recognise these infections.

\section{References}

${ }^{1}$ Lutwick LI, Galgiani JN, Johnson RH, Stevens DA. Visceral fungal infections due to Petriellidium boydii (Allescheria boydii). Am $\mathcal{F} \mathrm{Med}$ $1976 ; 61: 632-40$.

${ }^{2}$ Lutwick LI, Rytel MW, Yanez JP, Galgiani JN, Stevens DA. Deep infections from Petriellidium boydii treated with miconazole. $\mathcal{F} A M A$ $1979 ; 241: 272-3$.

3 Hayden G, Lapp C, Lada F. Arthritis caused by Monosporium apiospermum treated with intra-articular amphotericin B. Am f Dis Child 1977;131: 927.

4 Ehrlich GE. Fungal arthritis. $\mathcal{F} A M A$ 1978;240:563.

5 Anonymous. Ketoconazole [Editorial]. Lancet 1982;i:319-20.

\title{
Energy intake and weight gain of very low birthweight babies fed raw expressed breast milk
}

\author{
S A SPENCER, W HENDRICKSE, D ROBERTON, D HULL
}

\begin{abstract}
The energy intake and weight gain of low birthweight infants (under $1500 \mathrm{~g}$ ) fed expressed breast milk were measured. Between the second and fourth weeks of life the mean energy intake was $577 \mathrm{~kJ}(138 \mathrm{kcals}) / \mathrm{kg} /$ day and the mean weekly increase in weight $119 \mathrm{~g} /$ week. Feeding energy-rich hind milk to two babies increased their energy intake but had little effect on their rate of weight gain. There appeared to be no correlation between energy intake and weight gain, probably owing to variation in the absorption of nutrients from expressed breast milk.

This study forms a basis for a comparison of weight gain in babies fed alternative regimens of artificial milks.
\end{abstract}

\section{Introduction}

The optimal feed for preterm infants weighing less than $1500 \mathrm{~g}$ at birth is still hotly disputed. Whereas the report of the Depart-

\footnotetext{
Department of Child Health, University Hospital, Queen's Medical Centre, Nottingham NG7 2UH

$S$ A SPENCER, MRCP, lecturer

W HENDRICKSE, MRCP, lecturer

D ROBERTON, MRCP, MD, registrar

D HULL, FRCP, professor
}

ment of Health and Social Security's Working Party on Human Milk Banks ${ }^{1}$ suggested that banked human milk is generally agreed to be the best feed for these babies, opponents maintain that the use of such milk is little short of dangerous. ${ }^{2}$ Questions regarding bacterial contamination, heat treatment of milk, and the nutritional adequacy of expressed breast milk are raised repeatedly. Manufacturers have responded by providing feeds with alternative formulae, which need to be evaluated. To facilitate this the growth of preterm infants receiving expressed breast milk must be defined. As expressed breast milk has a very variable composition, particularly with regard to its energy content, ${ }^{3}$ any study would have little value unless some measure of the volume taken and energy content of expressed breast milk was made against which artificial milk formulae could be compared. This paper reports the weight increments of babies weighing less than $1500 \mathrm{~g}$ reared on breast milk, the energy content of which was estimated using a creamatocrit.

\section{Methods}

All surviving babies born in or transferred to Nottingham between February 1981 and February 1982 with a birth weight of less than $1500 \mathrm{~g}$ and a gestational age of less than 33 weeks whose mothers wished to provide expressed breast milk were eligible for study. Babies were excluded if total intravenous alimentation apart from dextrose alone was required or if ventilation was required beyond the end of the first week. The study was stopped in an individual baby when the baby was discharged or transferred out of Nottingham or the predominant feed was changed from expressed breast milk to an artificial milk. 
The babies were fed with their mother's expressed breast milk whenever possible, but additional milk was occasionally obtained from other mothers of preterm infants and from volunteers drawn from the National Childbirth Trust. All milk was given raw within 24 hours of expression. A proprietary milk feed (Gold Cap SMA) was given when no expressed breast milk was available. Babies were fed nasogastrically or nasojejunally as much milk as they would tolerate as judged by the nurse looking after them. Large volumes of gastric aspirate, vomiting, or abdominal distension were taken as indications to reduce the volume of feed. The maximum volume offered on the first day was $90 \mathrm{ml} / \mathrm{kg}$, and this maximum was increased by $30 \mathrm{ml} / \mathrm{kg}$ / day in a stepwise fashion. Babies receiving continuous feeds were fed using a vertically positioned syringe pump to minimise the loss of fat. ${ }^{3}$ In two mothers who produced copious volumes of milk the hind milk was selectively given to the infants.

The energy content of each sample of milk used was calculated from the creamatocrit, which was measured by the nurse responsible for feeding the child. To save nursing time the method used was modified from that previously described, ${ }^{4}$ the milk being centrifuged for only five minutes instead of 15 . This minor deviation was validated by correlation of the five-minute with the 15-minute creamatocrit in 32 samples of milk: there was a highly significant correlation $(p \ll 0.001)$ between the two creamatocrits, and the regression line did not differ significantly from the line of unity. The energy given for the week was derived by summing the energy contained in each sample given. Inevitably some expressed breast milk was given without a creamatocrit having been performed, and in these cases the milk was assumed to have contained the same energy content $/ 100 \mathrm{ml}$ as the accumulated milk with measured creamatocrit. Any additional energy given as intravenous dextrose or SMA was also taken into consideration when the daily energy intake was calculated, as a mean value over the week.

All babies were weighed three times weekly using a Marsden weighing machine, which is accurate to $10 \mathrm{~g}$. The weight on the first day of each week of feeding was used to calculate the energy given $/ \mathrm{kg}$; when this was not available it was calculated assuming equal weight increments between measurements.

\section{Results}

Fourteen babies completed two or more consecutive weeks of feeding with expressed breast milk but only eight completed four or more weeks. The data for these eight babies were analysed in more detail: they had a mean gestational age of 29 weeks and a mean birth weight

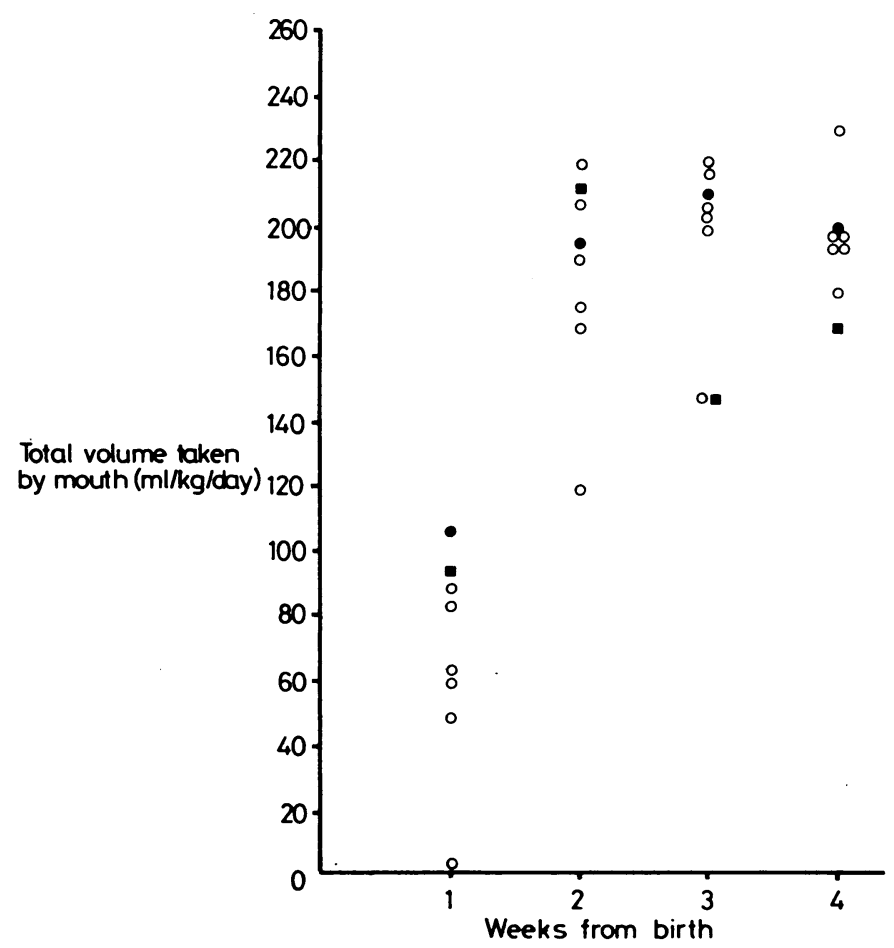

FIG 1-Mean daily volume of milk taken by mouth by eight infants in each of first four weeks of life. Two infants received mainly hind milk: $\square=$ case 1 ; $=$ case 3 . of $1100 \mathrm{~g}$ (table). Creamatocrits were obtained for more than $75 \%$ of the feeds of expressed breast milk given during weeks $2-4$ in more than $70 \%$ of weeks. No infant received less than $75 \%$ of its weekly energy as expressed birth milk after the first week.

Figures 1 and 2 show the mean daily intake of milk by volume and energy for each of the first four weeks of life; figure 3 shows the incremental weight gain over these weeks. During week 1 the babies took a

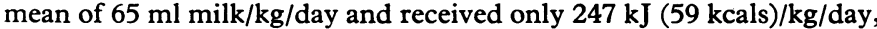

Birth weights and gestational ages in eight babies fed predominantly expressed breast milk for four consecutive weeks

\begin{tabular}{lccccccccr}
\hline Case No: & $1^{*}$ & \multicolumn{1}{c}{$3^{*}$} & \multicolumn{1}{c}{4} & \multicolumn{1}{c}{5} & \multicolumn{1}{c}{6} & \multicolumn{1}{c}{7} & 8 Mean \\
\hline Gestational age (weeks): & 26 & 29 & 29 & 28 & 31 & 32 & 30 & 30 & 29 \\
Birth weight (g): & 860 & 970 & 1035 & 1040 & 1090 & 1210 & 1300 & 1300 & 1100
\end{tabular}
Birth weight $(\mathrm{g})$ :

*Babies fed mainly hind milk.

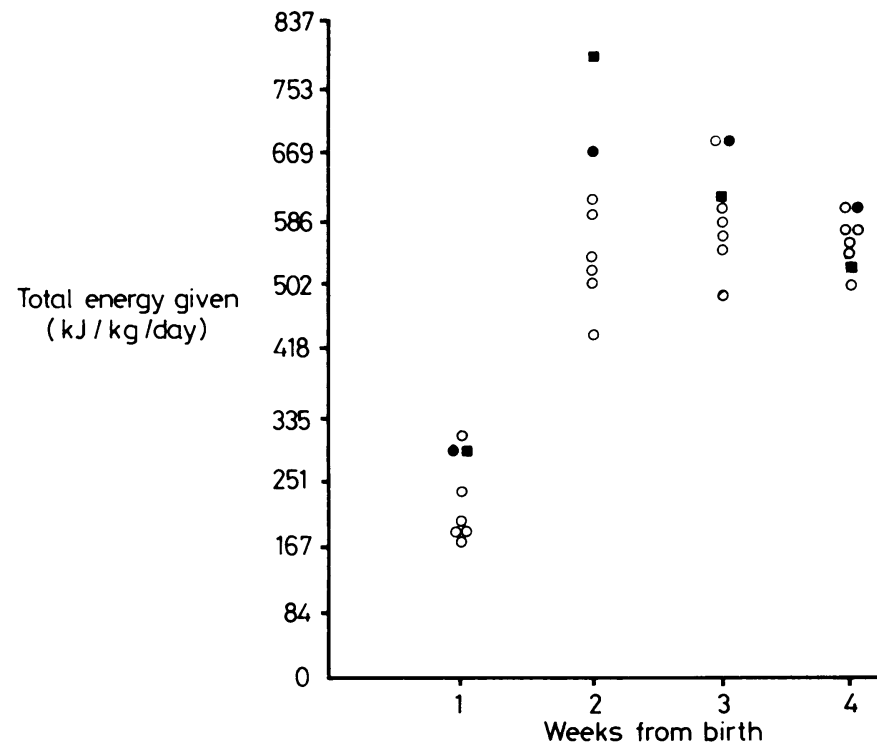

FIG 2-Mean daily energy intake in eight infants in each of first four weeks of life. Two infants received mainly hind milk: $\square=$ case $1 ; 0=$ case 3 . Conversion: SI to traditional units-Energy: $1 \mathrm{~kJ} \approx 0.24 \mathrm{kcal}$.

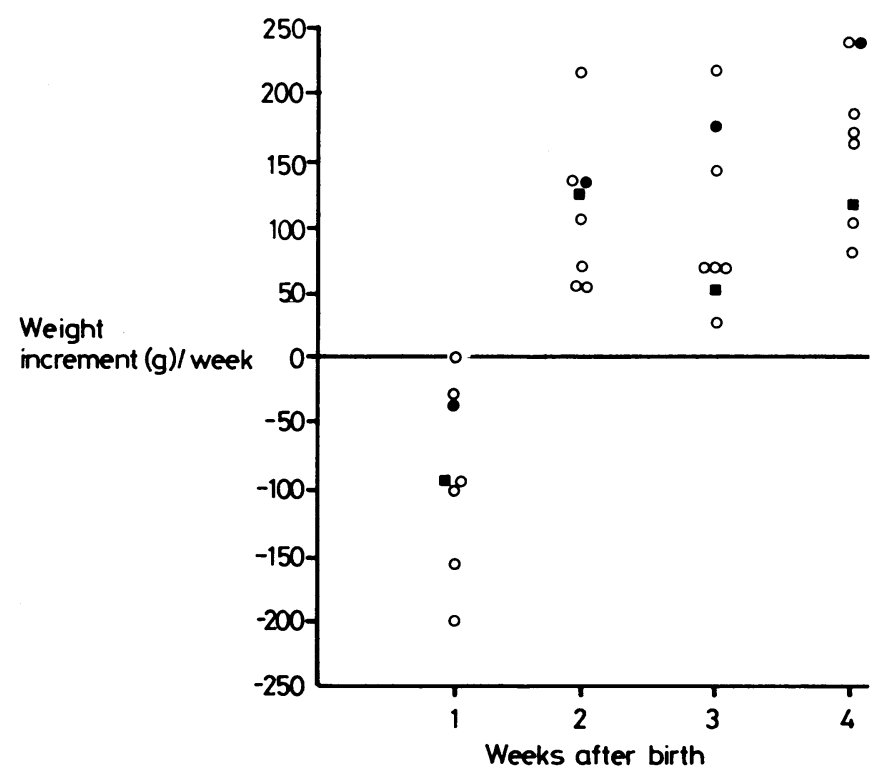

FIG 3-Weekly increments in weight in eight babies fed predominantly expressed breast milk for first four weeks of life. Two infants received mainly hind milk: $\mathbf{v}=$ case 1 ; $0=$ case 3 . 
including energy derived from intravenous dextrose, but in subsequent weeks they tolerated a mean of $190 \mathrm{ml} / \mathrm{kg} /$ day and received $577 \mathrm{~kJ}$ $(138 \mathrm{kcals}) / \mathrm{kg} /$ day as a result. The babies receiving mainly hind milk in the first three weeks tolerated a similar amount of milk (fig 1 ) and as a result had a high energy intake. This, however, did not result in a particularly high incremental weight gain (fig 3). The mean increase in weight over weeks $2-4$ was $119 \mathrm{~g} /$ week. On four occasions, however, weight increments of over $240 \mathrm{~g} /$ week were achieved.

Data on all 14 babies were used to correlate weekly weight gain against total energy intake in those babies who received less than $5 \%$ of the week's energy intravenously and more than $75 \%$ of the week's energy as expressed breast milk. There was no correlation between energy intake (mean $586 \mathrm{~kJ}(140 \mathrm{kcal}) / \mathrm{kg} /$ day) and weight gain (mean $108 \mathrm{~g} / \mathrm{kg} /$ day) (fig 4).

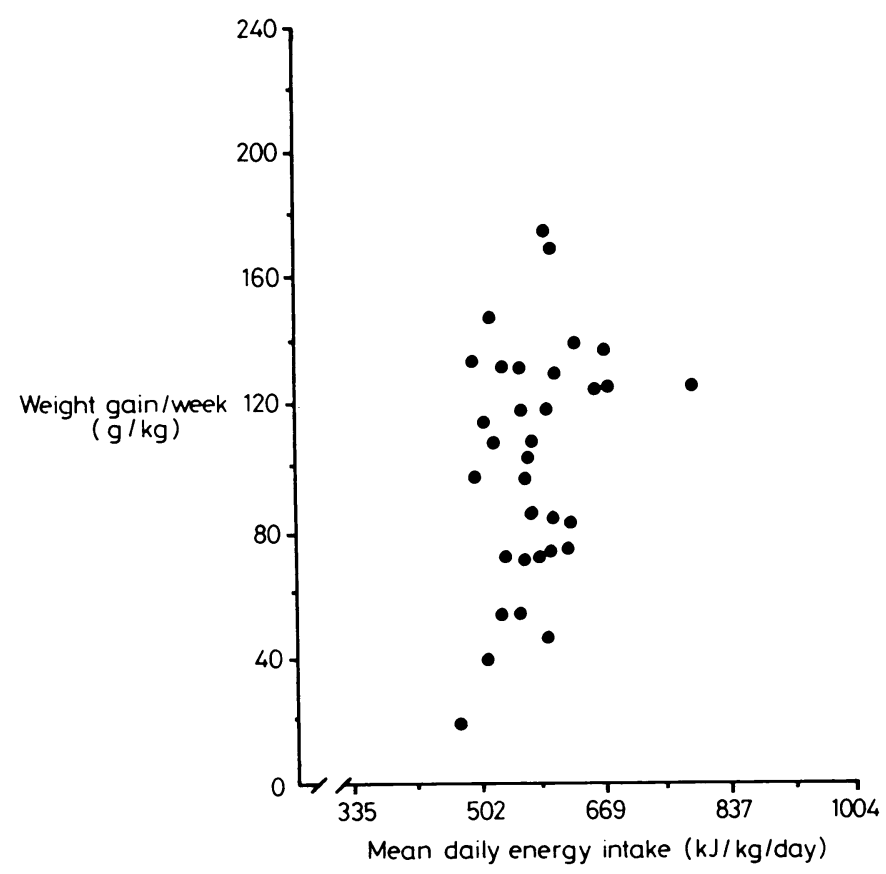

FIG 4-Mean energy intake against incremental weight gain $/ \mathrm{kg} /$ week in 14 babies from week 2 onwards.

Conversion: SI to traditional units-Energy: $1 \mathrm{~kJ} \approx 0 \cdot 24 \mathrm{kcal}$.

\section{Discussion}

Despite the strong controversy surrounding the practice of feeding expressed breast milk to very low birthweight babies little is known about weight gain in these babies during the critical first four weeks of life. Existing data, which have been used to call into question the nutritional adequacy of expressed breast milk, have been derived from studies using banked milk, ${ }^{56}$ which has different characteristics from a mother's own milk, both in terms of composition ${ }^{7}$ and absorption of its fats. ${ }^{8}$ When raw expressed breast milk has been used ${ }^{9}$ comparison of data is difficult because of the effect of birth weight on subsequent weight gain; nevertheless, the results are similar to those of our study. Our data are unique, since we were able to define the energy intake of babies who were receiving raw expressed breast milk; this will provide a sound basis for comparison with babies receiving other types of feed, either artificial or of enriched breast milk. ${ }^{10}$ An estimate of the energy requirement for the fetus for metabolism and growth during the last trimester is $277-418 \mathrm{~kJ}(90-100 \mathrm{kcal}) / \mathrm{kg} .{ }^{11}$ We have shown that this requirement is usually well exceeded after the end of the first week when very small babies are fed expressed breast milk.

Interestingly, we could not show a correlation between energy intake and weight gain. The possible reasons for this are $\underline{\underline{T}}$ variation in energy absorption, variation in metabolic rate, or 3 that weight gain does not represent accumulation of energy. $\mathbb{Q}$ Brooke et al showed using a formula feed ${ }^{12}$ that absorption of $c$ nutrients varies greatly both from day to day and between $\bar{\Omega}$ different immature babies. Although a substantial variation in $\bar{\Xi}$ metabolic rate was also seen, there was a strong correlation between weight gain and energy retained. A large variation in the absorption of nutrients from expressed breast milk would account for the large variation in weight gain seen in our study despite the relatively small variation in energy intake.

The two babies who received a high-fat diet did not seem to benefit particularly, which suggests that they may not have absorbed any more energy than those babies who received standard expressed breast milk. If absorption of untreated breastmilk fat is limited in the first few weeks of life then the wisdom of using expressed breast milk with a high creamatocrit or enriched breast milk $^{10}$ is questionable. The protein content of expressed breast milk also varies, ${ }^{7}$ but we were unable to measure this in the milk given to our babies. Possibly protein energy is better absorbed than lipid energy.

Although we found a mean weight gain of about $120 \mathrm{~g} /$ week, under exceptional circumstances weight gains of $240 \mathrm{~g} /$ week were seen. Any study of growth in very low birthweight babies is bedevilled by acute medical problems that interrupt feeding for a day or two or may have a more subtle effect on the absorption of nutrients. ${ }^{12}$ Might these large weight gains represent optimal growth, occurring when the infant's health and environment are most favourable? Weight gain of this magnitude if sustained would easily exceed figures quoted for intrauterine growth rates, ${ }^{5}$ and the infants would end up larger than normal babies at term. This raises more questions. Should we be aiming to sustain this high rate of growth, by using either selected breast milk or a formula, or should we be aiming for something less ? Is optimal growth less than that which is actually possible with a mother's own milk? If so by what criteria should we judge our feeding regimens?

We thank the nursing staff working on the Nottingham city neonatal intensive care unit and the Queen's Medical Centre special care baby unit for their help, and in particular for measuring hundreds of creamatocrits, which made this study possible.

\section{References}

${ }^{3}$ Lloyd J, compiler. The collection and storage of human milk. London: HMSO, 1981. (Reports on Health and Social Subjects No 22, DHSS.) Barrie H. Human milk banks. Lancet 1982;i :284.

${ }^{3}$ Spencer SA, Hull D. Fat content of expressed breast milk: a case for quality control. $\mathrm{Br} \mathrm{Med} \mathcal{F} 1981 ; 282: 99-100$.

4 Lucas A, Gibbs JAH, Lyster RLJ, Baum JD. Creamatocrit: simple clinical technique for estimating fat concentration and energy value of human milk. $\mathrm{Br}$ Med F 1978;i :1018-20.

${ }^{5}$ Davies DP. Adequacy of expressed breast milk for early growth of preterm infant. Arch Dis Child 1977:52:296-301.

6 Tyson J, Lasky R, Mize C, White R. Growth and development of infants $<1500 \mathrm{~g}$ fed banked human milk or premature formula. [Abstract.] Pediatr Res 1981;15:549.

7 Gross SJ, David RJ, Bauman L, Tomarelli RM. Nutritional composition of milk produced by mothers delivering preterm. $\mathcal{F}$ Pediatr 1980;96: 641-4.

Williamson S, Finucane E, Ellis $\mathrm{H}$, Gamsu HR. Effect of heat treatment of human milk on absorption of nitrogen, fat, sodium, calcium and phosphorus by preterm infants. Arch Dis Child 1978;53:555-63.

9 Pearce JL, Buchanan LF. Breast milk and breast feeding in very low birth weight infants. Arch Dis Child 1979;54:897-9.

10 Lucas A, Lucas PJ, Chavin SI, Lyster RLG, Baum JD. A human milk formula. Early Hum Dev 1980;4:15-21.

11 Sparks JW, Girard JR, Battaglia FC. An estimate of the caloric requirements of the human fetus. Biol Neonate 1980;38:113-9.

12 Brooke OG, Alvear J, Arnold M. Energy retention, energy expenditure and growth in health immature infants. Pediatr Res 1979;13:215-20. 